\title{
Villous papilloma of the appendix associated with mucocoele and intussusception
}

\author{
A. J. DARBY \\ M.B., B.S., M.R.C.Path. \\ A. DOCTOR \\ M.S., F.R.C.S. \\ Departments of Histopathology and Surgery, Northwick Park Hospital, \\ Harrow, Middlesex
}

\begin{abstract}
Summary
A case of villous papilloma of the appendix, associated with mucocoele formation and intussusception, is described. The literature is reviewed and it appears that there is no previous report of this association. It is suggested that so-called malignant mucocoeles of the appendix arise from pre-existing villous papillomas.
\end{abstract}

\section{Introduction}

Villous papilloma of the appendix is a rare tumour and needs to be distinguished from the more common, invasive adenocarcinoma.

Although intussusception of the appendix has been found together with mucocoele formation (Mann, Wolf and Greenblatt, 1964), there appears to have been no description of either of these conditions in association with a villous papilloma.

\section{Case report}

An 85-year-old woman was referred for investigation of anaemia. She was complaining of general ill health since the death of her son, 3 years previously. Her appetite was poor and she had lost $6 \mathrm{~kg}$ in weight. There was no history of abdominal pain, nausea, vomiting or change in bowel habit. Eighteen months before, an X-ray for back pain had revealed the presence of Paget's disease of the pelvis. She had long-standing atrial fibrillation and 3 years before had suffered a myocardial infarction. She was currently being treated with digoxin and diuretics for cardiac failure.

On examination her pulse was $100 / \mathrm{min}$ and she was in atrial fibrillation. An aortic, systolic murmur was heard, but her heart condition was under control. A firm mass, $15 \times 15 \mathrm{~cm}$, with an irregular, lobular outline was felt in the right iliac fossa and right loin. It appeared to be fixed to underlying tissues and was dull to percussion. Rectal examination was normal. There was no ascites and the liver and spleen were

Correspondence: Dr A. J. Darby, Department of Pathology, Radcliffe Infirmary, Oxford OX2 6HE. impalpable. A provisional diagnosis of carcinoma of the caecum was made.

Investigations. $\mathrm{Hb} 10.6 \mathrm{~g} / 100 \mathrm{ml}$; WCC $10,600 /$ $\mathrm{mm}^{3}$ with a normal differential count; PCV $31.4 \%$ and ESR (Westergren) $115 \mathrm{~mm} / \mathrm{hr}$. The patient was unable to retain a barium enema, but barium meal and follow-through showed medial displacement of the caecum and ascending colon by a large, soft tissue mass. There was also a filling defect, about 4 $\mathrm{cm}$ in diameter, in the caecum.

At laparotomy in August 1971 (Mr Alan G. Cox), a large mass in the right iliac fossa was immediately obvious. Further exploration revealed that the base of the appendix had intussuscepted into the caecum, where a tumour could be felt. The distal part of the appendix opened into an enormous cystic swelling in the iliac fossa which was firmly attached to all surrounding structures (Fig. 1).

A right hemicolectomy was performed, removing the caecum and its enclosed tumour together with the appendix up to its junction with the cyst and the terminal $15 \mathrm{~cm}$ of ileum. Removal of the cystic mass was judged to be hazardous because of its fixity. The cyst was therefore opened and $500 \mathrm{ml}$ of glutinous, yellow material was aspirated. The opening in the cyst was sutured around a large tube drain inserted into the cavity through a stab incision made in the right iliac fossa. Alimentary continuity was then restored by ileo-transverse anastomosis.

The operative findings suggested that there was a tumour of the base of the appendix which had intussuscepted into the caecum and was associated with massive mucocoele formation.

Pathology. Dissection of the specimen revealed a lobulated, cauliflower-like tumour, $6.5 \times 3.5 \mathrm{~cm}$, which had arisen from the mucosa of the base of the appendix and intussuscepted into the caecum. The appendiceal mucosa distal to the tumour had a thickened, shaggy appearance (Fig. 2).

The histological appearance was that of a villous papilloma (Fig. 3). Microscopy showed a branching, papillary tumour composed of fronds of tissue in 


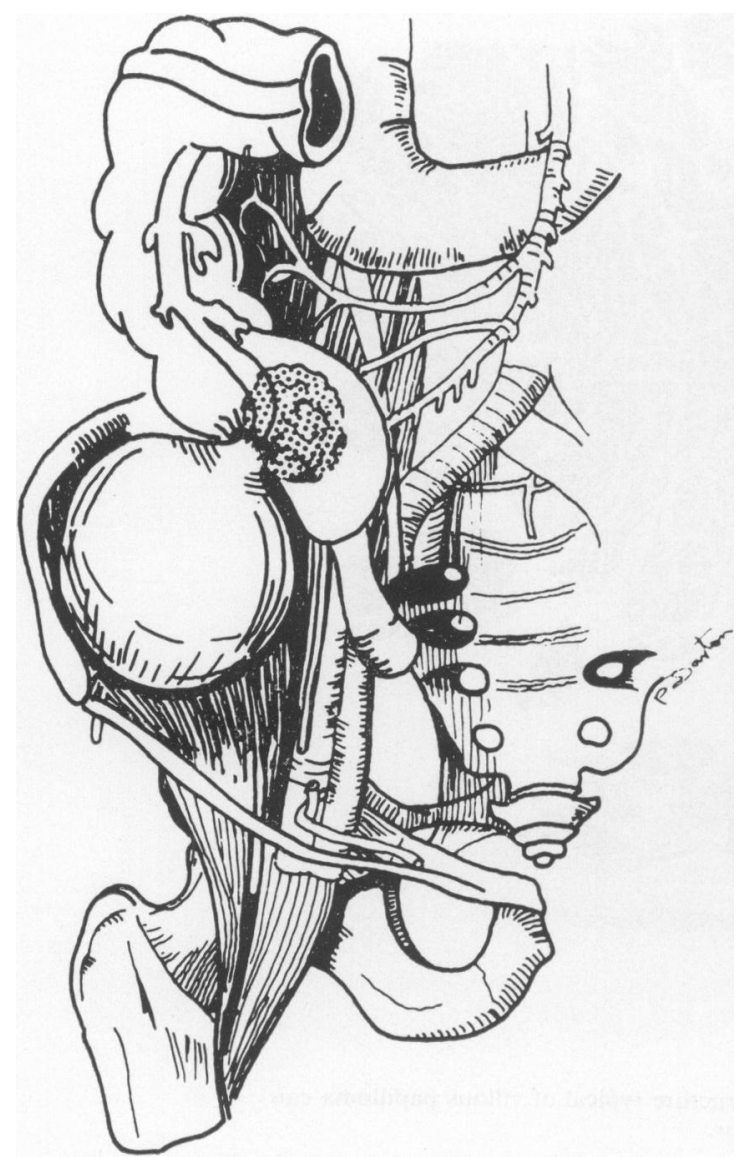

Fig. 1. Diagram of the findings at laparotomy showing the large mucocoele of the distal appendix. The tumour at the base of the appendix (stippled area) has intussuscepted into the caecum.

which a tall, columnar epithelium containing numerous mucus-secreting, goblet cells covered a narrow, fibrovascular stroma. Although hyperchromatic, pleiomorphic nuclei and frequent mitoses were seen in some areas, multiple sections failed to reveal any evidence of invasion. The macroscopical appearance of the mucosa distal to the papilloma was caused by extension of the tumour, in a sessile fashion, up to the line of resection. Here, the microscopical appearance was similar to that seen in the main body of the tumour but lacked its luxuriant, papillary arborization. There was no spread proximally, but in the caecum a small, adenomatous polyp, $0.5 \mathrm{~cm}$ in diameter, was noted. The mesenteric lymph nodes were free from tumour.

The patient made a good recovery and was alive and well 18 months following her operation.

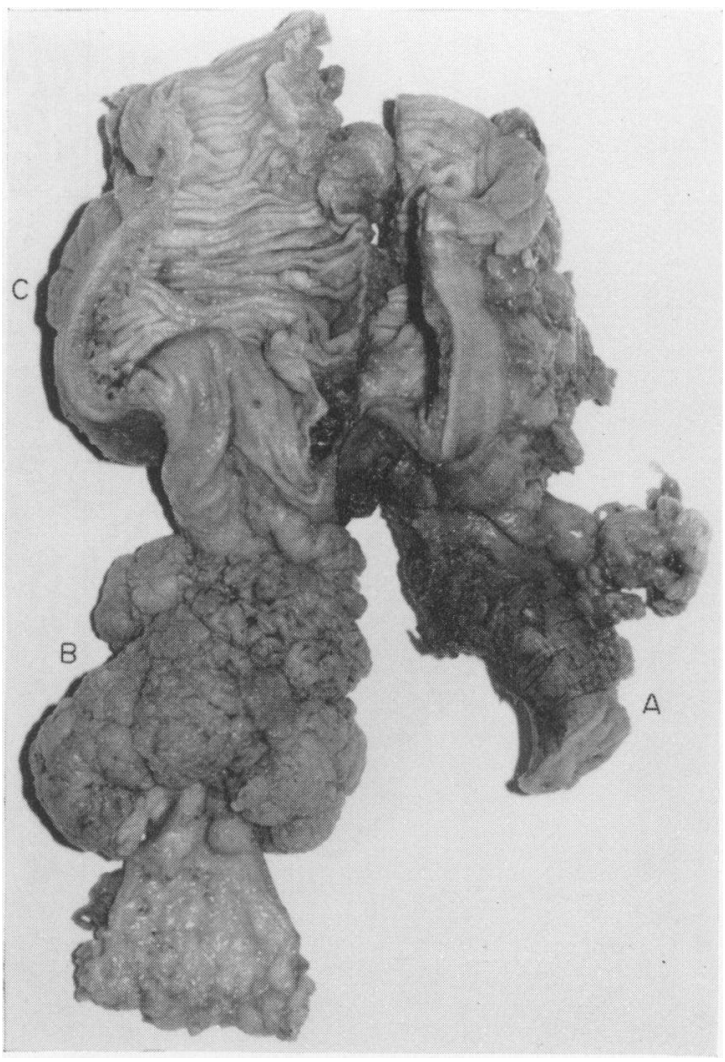

Fig. 2. In the opened specimen, after reduction of the intussusception, the terminal ileum (A), villous papilloma (B) at the base of the appendix, and caecum (C) are identified.

\section{Discussion}

Villous papilloma was first described as a distinct entity by Quénu and Landel in 1899; but it was not until 1948, when Sunderland and Binkley published their large series of cases, that a separate classification was generally accepted. Forty-eight villous papillomas, all arising in either the sigmoid colon or rectum, were found in a total of 3356 benign and malignant tumours of the large intestine (Sunderland and Binkley, 1948). Their occurrence in the proximal colon is rare (Goldfarb, 1964). The malignant potential of villous papilloma is well known; but, whether or not it is greater than that of the more common, adenomatous polyps, is still unproven (Spratt, Ackerman and Moyer, 1958; Castleman and Krickstein, 1962; Morson, 1968).

Villous papilloma of the appendix is extremely rare. In the literature, we have found only ten cases in which the histological appearance corresponds with that originally described by Quénu and Landel (1899) (Table 1). Hameed (1966) reported one of 


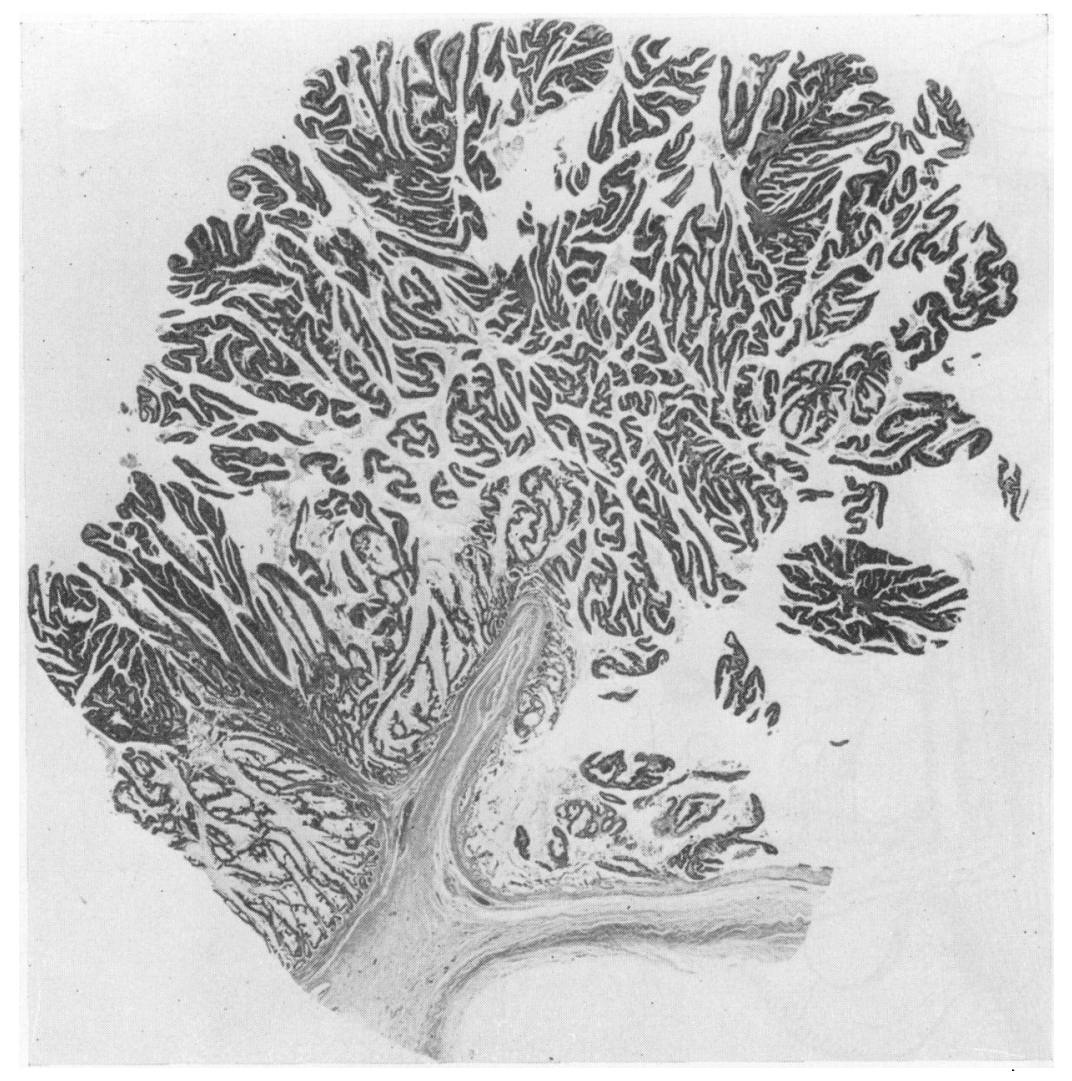

FIG. 3. The delicate, arborizing, papillary structure typical of villous papilloma can be seen in a histological section of the tumour.

these and discussed what he claimed were thirty-four others. However, most of these cases were not considered originally to be villous papillomas, and in only five are the illustrations and descriptions consistent with such a diagnosis. The distinction between a potentially malignant tumour, such as villous papilloma, and invasive carcinoma is obviously important (Morson, 1968). In at least one instance, a reported villous papilloma of the appendix is, in fact, a description of invasive, papillary adenocarcinoma (Vander and Mandell, 1968).

Intussusception of the appendix is another uncommon but well documented occurrence (Fraser, 1943). A variety of factors, such as tumours, foreign bodies and inflammation are associated with this condition and have been cited as being aetiological agents (Fraser, 1943). An unusual case of intussusception, described by Burghard in 1914, was one in which the tip of the appendix presented at the anus and was excized following an erroneous diagnosis of prolapsed rectal polyp. When the excized specimen was examined, a papillomatous tumour was found arising from the base of the appendix, but, unfortunately, no histology was reported.

Mucocoele formation has been found in $0.245 \%$ of 71,000 appendix specimens, an incidence of about 1 in 400 (Collins, 1963). Mucocoeles are usually said to follow post-inflammatory stricture, but obstruction due to carcinoid tumours or adenocarcinoma is also recognized (Hughes, 1967). A distinction has been made between benign and malignant forms of mucocoele, and the latter have been said to result from a neoplastic change in the epithelial lining of a simple mucocoele (Woodruff and McDonald, 1940).

None of the cases of villous papilloma in Table 1 was associated either with mucocoele formation or intussusception. Moreover, most of them were discovered either coexisting with acute appendicitis or following incidental appendicectomy. Thus, the natural history of these tumours is not known.

Because of the intimate association, in our case, of a mucocoele and intussusception with a villous 


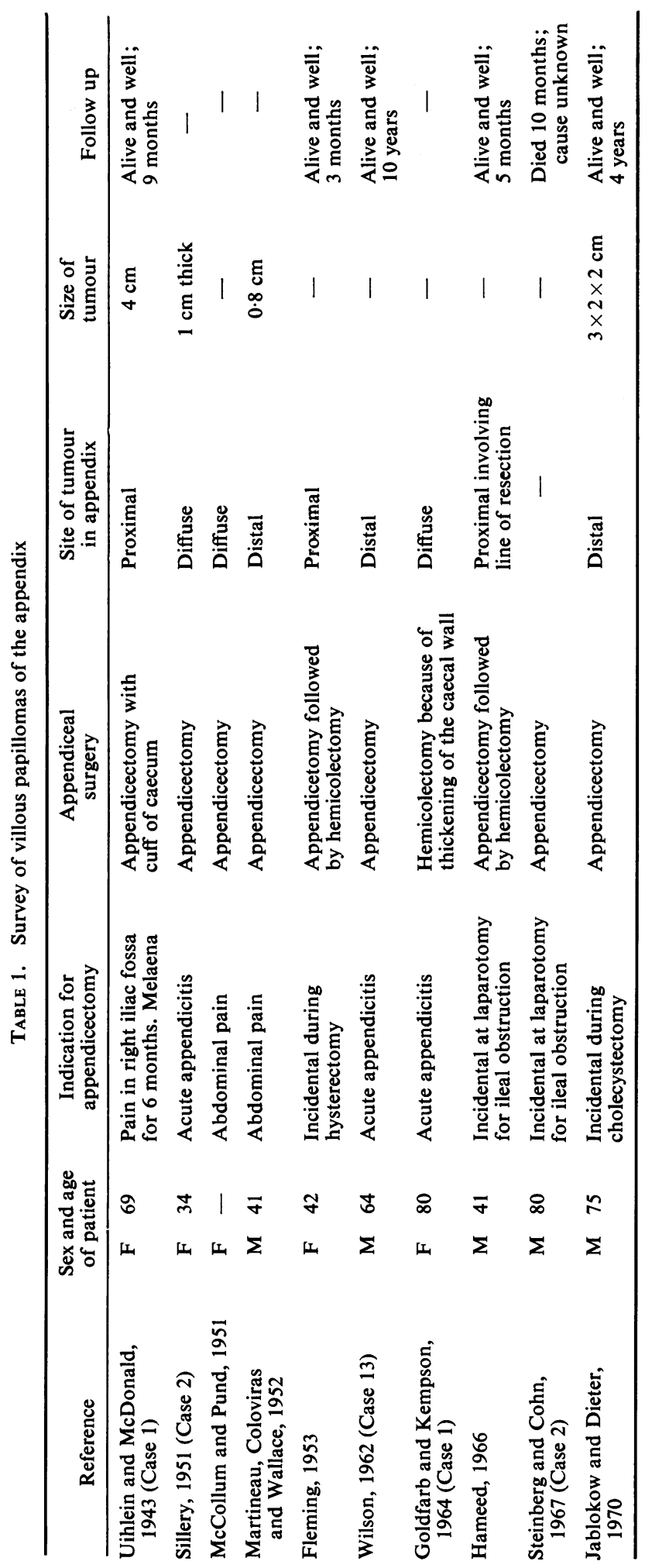

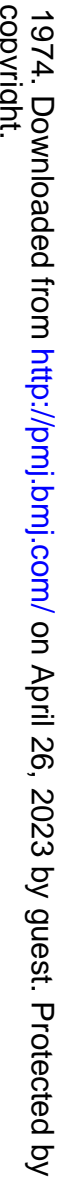


papilloma of the appendix, it is probable that all three are sequentially interrelated. An initial, mucussecreting, polypoid, villous papilloma could have intussuscepted into the caecum, resulting in obstruction of the proximal appendix. This together with abundant mucus secretion would have led to massive mucocoele formation. Since sessile tumour was found right up to the line of resection, it almost certainly extends into the lining of the unexcized mucocoele. Moreover, it seems clear from the histological descriptions and illustrations of Woodruff and McDonald (1940), that their grade I cystadenocarcinomas of the appendix are, in fact, mucocoeles lined with villous papilloma. We would, therefore, suggest that some, if not all, so-called malignant mucocoeles or grade I cystadenocarcinomas of the appendix result from excess mucus secretion from a sessile villous papilloma and not from any malignant change in the wall of a benign mucocoele.

For our patient, the prognosis must be guarded. It is likely that at least part of the unremoved mucocoele is lined with villous papilloma and the possibility of any future development of invasive tumour or pseudomyxoma peritonei cannot be excluded.

\section{Acknowledgments}

We wish to thank Mr Alan G. Cox and Dr G. Slavin for permission to report this case, and for their advice in the preparation of the manuscript. We also thank Mr P. Darton for Fig. 1.

\section{References}

BURGHARD, F.F. (1914) Intussusception of the vermiform appendix, the intussusceptum protruding from the anus. British Journal of Surgery, 1, 721.

Castleman, B. \& Krickstein, H.I. (1962) Do adenomatous polyps of the colon become malignant? New England Journal of Medicine, 267, 469.

Collins, D.C. (1963) 71,000 Human appendix specimens: a final report, summarizing forty years' study. American Journal of Proctology, 14, 365.

Fleming, J.M. (1953) Primary carcinoma of the vermiform appendix. American Journal of Surgery, 86, 188.
Fraser, K. (1943) Intussusception of the appendix. British Journal of Surgery, 31, 23.

GolDFARB, W.B. (1964) Villous adenomas of the right colon. Cancer, 17, 264.

GoldFARB, W.B. \& Kempson, R. (1964) Villous adenomas of the appendix. Surgery, 55, 769.

HAMEED, K. (1966) Villous adenoma of the vermiform appendix. A review with report of a case. Archives of Pathology, 81, 465.

Hughes, J. (1967) Mucocele of the appendix with pseudomyxoma peritonei: a benign or malignant disease? Annals of Surgery, 165, 73.

JABlokow, V.R. \& Dieter, R., JR (1970) Papillary (villous) adenoma of the vermiform appendix. American Journal of Gastroenterology, 53, 72.

ManN, L.S., Wolf, A. \& Greenblatt, M. (1964) Intussusception due to mucocele of the appendix. Surgery, 55, 672.

Martineau, P.C., Coloviras, G.J. \& Wallace, S.M. (1952) Adenomatous appendicular polyps. Journal of the American Medical Association, 149, 1548.

McCollum, W. \& Pund, E.R. (1951) Preinvasive adenocarcinoma of the appendix. Report of sixteen cases. Cancer, 4, 261.

MoRSON, B.C. (1968) Precancerous and early malignant lesions of the large intestine. British Journal of Surgery 55, 725.

Quenu, E. \& LANDEL, G. (1899) Des tumeurs villeuses ou épithéliomas superficiels végétants du rectum. Revue de Gynécologie et de Chirurgie abdominal, 3, 95.

Sillery, R.J. (1951) Primary carcinoma of the appendix. A report of two cases. Journal of the American Medical Association, 147, 854.

Spratt, J.S., JR, ACKerman, L.V. \& Moyer, C.A. (1958? Relationship of polyps of the colon to colonic cancer: Annals of Surgery, 148, 682.

Steinberg, M. \& CoHN, I., JR (1967) Primary adenocarci noma of the appendix. Surgery, 61, 644.

Sunderland, D.A. \& Binkley, G.E. (1948) Papillary adenomas of the large intestine. A clinical and morphological study of forty-eight cases. Cancer, 1, 184.

Uihlein, A. \& McDonald, J.R. (1943) Primary carcinoma of the appendix resembling carcinoma of the colon. Surgery, Gynecology and Obstetrics, 76, 711.

VANDER, S.A. \& MANDELL, G.H. (1968) Villous adenoma of the appendix. Report of a case. Archives of Surgery, 97 562.

Wilson, R. (1962) Primary carcinoma of the appendix. American Journal of Surgery, 104, 238.

WoodrufF, R. \& McDonAlD, J.R. (1940) Benign and malignant cystic tumors of the appendix. Surgery, Gynecology and Obstetrics, 71, 750. 